\title{
Intergenerational Persistence of Earnings: The Role of Early and College Education ${ }^{\dagger}$
}

\author{
Diego Restuccia
}

University of Toronto

\section{Carlos Urrutia}

Centro de Investigación Económica, ITAM

Universidad Carlos III de Madrid

September 2002

\begin{abstract}
Recent empirical studies show that the intergenerational persistence of economic status in the U.S. is much higher than previously thought. We develop a quantitative theory of inequality and intergenerational transmission of human capital where parents invest in early and college education of their children subject to borrowing constraints. Children differ exogenously in innate abilities, which can be correlated with their parent's innate ability. An important feature of the environment is that the quality of early education determines the probability of college completion. We calibrate a stationary equilibrium of this economy to relevant statistics in aggregate U.S. data, and use it to investigate the sources of inequality and persistence in earnings. In our benchmark model, about half of the intergenerational persistence and one fourth of the inequality in earnings are accounted for by endogenous investments in education. We find that early investments in education account for most of the endogenous persistence in earnings, while college education generates most of the endogenous inequality in earnings. Our theory is suited to study the effect of educational policies on the persistence of inequality. We show that public resources devoted to early education have the largest impact on earnings mobility. Moreover, non-progressive college subsidies generate more intergenerational persistence of earnings.
\end{abstract}

Keywords: Human Capital, Education, Intergenerational Mobility, Ability. Journal of Economic Literature Classification Numbers: I2, E6, J62.

\footnotetext{
${ }^{\dagger}$ We would like to thank Andrés Erosa, Ig Horstmann, and Todd Stinebrickner for extensive comments and discussions about this research. We have benefited from numerous comments of seminar participants at several universities and conferences. Restuccia acknowledges the financial support from the Connaught Fund at the University of Toronto and the Social Sciences and Humanities Research Council of Canada. Urrutia thanks the Vicerrectorado de Investigación at Universidad Carlos III de Madrid and the Ministry of Education of Spain (DGESIC) for research grants. Contact Information: currutia@itam.mx and diego.restuccia@utoronto.ca
} 


\section{Introduction}

The degree to which economic status is transmitted across generations is of great importance because it represents a measure of the degree of equality of opportunities in a society. Recent empirical estimates of the intergenerational mobility in income, earnings, consumption, and other relevant measures of economic status have found low degrees of mobility in the U.S. economy $^{1}$. As an example, a general finding is that the intergenerational persistence in earnings, measured as the slope coefficient obtained by regressing children's log earnings when adults against parents' log earnings, is around 0.4 . That is, around $40 \%$ of parents relative position in the distribution of earnings is transmitted to their children.

Our aim in this paper is to identify and measure the major sources of intergenerational mobility. To do so, we develop a quantitative theory of inequality and intergenerational transmission of human capital. Numerous studies emphasize the importance of early childhood education in determining future outcomes ${ }^{2}$. Our model incorporates this element by having parents invest in both early and college education of their children. Both sorts of investments are subject to borrowing constraints. In this environment we study the role of human capital investments in accounting for inequality and persistence of earnings. We find that about half of earnings persistence and one fourth of earnings inequality are accounted for by endogenous investments in education. Moreover, early investments in education account for most of the endogenous persistence in earnings, while college education generates most of the endogenous inequality in earnings.

Our analysis is not the first to attribute intergenerational persistence to human capital investments. Becker and Tomes (1979) emphasize innate ability transmission with borrowing constraints to human capital investments. Loury (1981) provides a similar analysis but without innate ability transmission across generations. Differently than these papers, ours is a quantitative assessment of the human capital contribution to persistence and inequality. More recently, calibrated general equilibrium models have been used to study the evolution of income and wealth distributions over time and across generations ${ }^{3}$. Differently than these previous models, ours features human capital investments as a two-stage process: early and college education. In our framework, we determine and quantify the relative importance of

\footnotetext{
${ }^{1}$ For surveys of these estimates, see Stokey (1999) and Solon (2000).

${ }^{2}$ See Neal and Johnson (1996), Keane and Wolpin (1997), Currie and Thomas (1999), and Heckman (2000).

${ }^{3}$ See Aiyagari, Greenwood, and Guner (2000), Regalía and Ríos-Rull (1999), Fernández and Rogerson (2001), Castañeda, Díaz-Giménez, and Ríos-Rull (2002), Knowles (1999), Aiyagari, Greenwood, and Seshadri (2001), and Erosa and Koreshkova (2001).
} 
early versus college education on both persistence and inequality. This relative importance is a crucial for policy analysis. Moreover, an important implication of the distinction between early and college education is that our model attributes differences in earnings within educational attainment groups to differences in early educational investment, rather than to an unrelated shock to earnings that is difficult to measure in the data.

Our theory of earnings inequality and persistence has the following features. The economy is populated by a large number of overlapping generations organized into dynasties. Each individual lives for four periods and population stays constant over time. In the first two periods, individuals make no decisions, obtain education, and work. In the last two periods, individuals work, make educational investment decisions for their children, and household consumption decisions. Individuals are born with innate abilities that may be correlated with parent's ability. Sacerdote (2002) and the references therein provide strong empirical evidence in support of both genetic and environmental factors determining lifetime economic status.

In the first period of life individuals acquire education of differing qualities depending on the resources spent by parents ${ }^{4}$. In the second period of life individuals may go to college, if parents pay a fixed cost, with a completion risk. The dropout probability depends on acquired ability in the first period of life ${ }^{5}$. Both early and college education can be paid for only out of current consumption (there is no borrowing or saving). While this latter assumption is quite strong, there is substantial evidence that borrowing constraints are important in determining parental investments in education, especially at the early education stage (see for instance Heckman, 2000 and Keane and Wolpin, 2001).

In our model investments in early education face a tighter borrowing constraint and are less risky than college investments. Both of these properties work to amplify the role of early education in generating persistence relative to college education. Borrowing constrained parents are more likely to have children with similar earnings. Since poor families tend to under-invest in their children's education, they are less likely to find it attractive to send their children to college. This selection property of college attendance makes borrowing constraints less severe at the college stage. Moreover, since college education faces a completion risk, this reduces persistence and increases inequality.

\footnotetext{
${ }^{4}$ Resources devoted to early education are an abstraction of many different interpretations: parent's time and human capital, teacher and school quality, foregone earnings of individuals in school, peer group effects, among others. Distinguishing between these different alternatives is an important topic for future research.

${ }^{5}$ This assumption is consistent with the evidence on college completion in Manski and Wise (1983) and Stinebrickner and Stinebrickner (2001).
} 
We use our theory to study the effects of government expenditures in early education and in college subsidies on the intergenerational persistence of earnings. The role of the government in providing for public funding to education has been recognized as an important instrument to enhance social mobility and equality of opportunities in a world with imperfect capital markets. We find that an increase in public resources devoted to early education have a larger impact on mobility than an increase in college subsidies, since these resources target young parents facing tighter borrowing constraints at a stage of decisions with important lifetime consequences. Moreover, moving from the current need-based college subsidy system to a flat subsidy would significantly increase the intergenerational persistence of earnings.

The paper proceeds as follows. In the next section, we describe the economic environment. In section 3, we parameterize and calibrate the benchmark economy to U.S. data. Section 4 reports the properties of the benchmark economy regarding inequality, persistence, and the cross-sectional correlations between variables of interest. In section 5 we illustrate the sources of persistence and inequality by shutting down one feature of the environment at a time, in particular, we consider an environment without innate ability correlation across generations, without early education, and without college education. Section 6 documents a set of policy experiments in education. Finally we conclude with some suggestions for future research.

\section{Economic Environment}

We develop a theory of inequality and intergenerational transmission of human capital that features both early investments in education and college education. We study the sources of inequality and persistence in this environment, as well as the impact of educational policies often discussed in public policy debates.

\subsection{General Description}

The economy is populated by individuals that live for four periods, two as children in their parent's household and two as adults. We refer to individuals starting their third period of life (this is, their first period as adults) as young parents. Each of these individuals, together with one newborn child, form a household unit that lasts for two periods. At the end of the second period the old parent dies and her child becomes a young parent, starting her own household. This process repeats itself over time. At each moment, there is a mass one of individuals of each age, so population is constant over time. 
We assume that parents make all the decisions, but they care about their children's utility. Young parents differ in their human capital and the innate ability of their children. Innate abilities are drawn from a common distribution, and may potentially be correlated across generations. With this information, young parents decide the household total consumption and the amount of resources devoted to their children's early (primary and elementary) education. Because we prevent agents from borrowing and lending, young parents might be credit constrained for early schooling investments.

Old parents differ in human capital and in what we call acquired ability of their children. The acquired ability of a child depends upon two things: innate ability and (private and public) expenditures in early education. Old parents decide whether to send their children to college and household consumption. The college option requires to pay both a fixed cost in resources and a time cost, and involves, as in Caucutt and Kumar (2001), a risk of no completion. A higher acquired ability is associated with a lower dropout probability. The resulting human capital of the child depends upon her acquired ability and college completion.

We abstract from physical capital and aggregate uncertainty in this economy. Output of the unique good in the economy is determined by a constant returns to scale technology that depends on aggregate human capital. We assume that individuals human capital are perfect substitutes in production.

There is a government that taxes labor income at an exogenously given and time invariant rate. The proceedings of this tax are used to provide public resources to early education, equally distributed among all children in early school age, and to subsidy college expenditures with a progressive scheme in which poor parents receive a higher subsidy. We assume the government balances its budget each period. We focus on a stationary equilibrium in this environment where all aggregate allocations and and prices are constant over time.

\subsection{Young Parents' Problem}

At the beginning of the period, a young parent has an individual state characterized by $x_{y} \equiv\left(h_{y}, \pi\right)$ where $h_{y}$ is human capital and $\pi$ is the realized innate ability of the child. In this general setup, we assume that innate abilities follow a first order discrete Markov process with mean normalized to one, $\pi_{\min }>0$, and transition matrix $\Phi$. By choosing appropriately the values in $\Phi$ (as described later) we can represent different degrees of intergenerational transmission of abilities, including the case of no innate ability transmission across generations. 
Given a wage rate $w$ and the amount of public spending in early education $g$, the problem of a young parent is described by the following functional equation,

$$
\begin{aligned}
& V_{y}\left(h_{y}, \pi\right)=\max _{c_{y}>0, e>0}\left\{u\left(c_{y}\right)+\beta V_{o}\left(h_{o}, \pi, \hat{\pi}\right)\right\}, \\
& \text { s.t. } \begin{aligned}
c_{y}+e & =(1-\tau) w h_{y}, \\
\hat{\pi} & =G(\pi, e, g), \\
h_{o} & =\xi h_{y},
\end{aligned}
\end{aligned}
$$

where $\tau$ is the income tax rate, $c_{y}$ denotes household's consumption, $e$ is expenditures in child's early education, and $\hat{\pi}$ represents old child's acquired ability. $G$ is a production function for human capital, increasing in its three arguments, transforming innate ability and expenditures into acquired ability. Parent's human capital when old is related to human capital when young by a coefficient $\xi>1$, capturing the life-cycle of earnings. The policy rules for consumption and early schooling expenditures in this problem are written as $g^{c_{y}}\left(x_{y}\right)$ and $g^{e}\left(x_{y}\right)$.

\subsection{Old Parents' Problem}

At the beginning of the period, an old parent faces the individual state vector $x_{o} \equiv\left(h_{o}, \pi, \hat{\pi}\right)$ where $h_{o}$ is human capital, $\pi$ is child's innate ability, and $\hat{\pi}$ is child's acquired ability. Innate ability of the child is a state variable for the old's parent since it may affect grandchild's innate ability depending on the intergenerational correlation of innate abilities. Given prices and the stochastic processes for innate abilities and college completion, the problem of an old parent is given by the following functional equation

$$
V_{o}\left(h_{o}, \pi, \hat{\pi}\right)=\max _{s \in\{0,1\}}\left\{V_{o}^{s_{0}}\left(x_{o}\right), E_{\theta} V_{o}^{s_{1}}\left(x_{o}, \theta\right)\right\}
$$

where $V_{o}^{s_{0}}\left(x_{o}\right)$ is the option value of no college education for the child and $V_{o}^{s_{1}}\left(x_{o}, \theta\right)$ is the option value of college education for the child conditional on the college completion shock $\theta$. We denote $\theta=1$ ( or $\theta_{1}$ ) the college completion and $\theta=0$ ( or $\left.\theta_{0}\right)$ the college dropout. The expected option value of college education is given by,

$$
E_{\theta} V_{o}^{s_{1}}\left(x_{o}, \theta\right)=q(\hat{\pi}) V_{o}^{s_{1}}\left(x_{o}, \theta_{1}\right)+(1-q(\hat{\pi})) V_{o}^{s_{1}}\left(x_{o}, \theta_{0}\right),
$$


where $q(\hat{\pi}) \in[0,1]$ is the probability of college completion. We assume that $q$ is an increasing function, with $q(0)=0$ and $q(\infty)=1$. Parents make the decision whether to send their child to college or not before knowing the realization of the college completion shock.

The option value of not sending the child to college is given by,

$$
\begin{aligned}
& V_{o}^{s_{0}}\left(x_{o}\right)=\max _{c_{o}>0}\left\{u\left(c_{o}\right)+\beta E_{\pi^{\prime}}\left[V_{y}\left(h_{y}^{\prime}, \pi^{\prime}\right) \mid \pi\right]\right\}, \\
& \text { s.t. } \quad c_{o}=(1-\tau)\left(w h_{o}+w h_{y}^{\prime}\right), \\
& \qquad h_{y}^{\prime}=\hat{\pi},
\end{aligned}
$$

where $c_{o}$ is household's consumption, $h_{y}^{\prime}$ is next period child's human capital, and $\pi^{\prime}$ is grandchild's innate ability.

The option value of college is given by,

$$
\begin{gathered}
V_{o}^{s_{1}}\left(x_{o}, \theta\right)=\max _{c_{o}>0}\left\{u\left(c_{o}\right)+\beta E_{\pi^{\prime}}\left[V_{y}\left(h_{y}^{\prime}, \pi^{\prime}\right) \mid \pi\right]\right\}, \\
\text { s.t. } \quad c_{o}+\left(1-\kappa\left(w h_{o}\right)\right) f[\theta \bar{n}+(1-\theta) \underline{n}]= \\
(1-\tau)\left(w h_{o}+w h_{y}^{\prime}[\theta(1-\bar{n})+(1-\theta)(1-\underline{n})]\right), \\
h_{y}^{\prime}=\theta \bar{p} \hat{\pi}+(1-\theta) \hat{\pi},
\end{gathered}
$$

where $f>0$ is the fixed resource cost of college education per unit of time measured in terms of the output good, $\bar{n}$ and $\underline{n}$ are the time cost of college education, for college completion and college dropout, and $\bar{p}$ is the individual college completion premium. Notice that dropouts receive no human capital premium. The function $\kappa\left(w h_{o}\right)$ represents a government subsidy received by parents for each unit of output spent in college education. We assume that $\kappa$ is a decreasing function of parent's earnings, with $\kappa(0) \leq 1$ and $\kappa(\infty)=0$, to represent a progressive subsidy scheme. The old parent's problem generates policy rules $g^{c_{o}}\left(x_{o}, s, \theta\right)$ and $g^{s}\left(x_{o}\right)$.

\subsection{Firm's Problem}

Under a constant returns to scale technology, the representative firm solves a static optimization problem defined by

$$
\max _{H>0}\{Y-w H\}
$$




$$
\text { s.t. } \quad Y=F(H) \text {. }
$$

We write $f^{H}$ as the optimal policy rule generated by this problem.

\subsection{Market Clearing Conditions}

Clearing in the human capital market requires

$$
\begin{gathered}
f^{H}(\mu)=H=\int h_{y} d \mu_{y}\left(x_{y}\right)+\int h_{o} d \mu_{o}\left(x_{o}\right)+ \\
\int\left\{\left[1-g^{s}\left(x_{o}\right)\right] \hat{\pi}+g^{s}\left(x_{o}\right)[\bar{p} \hat{\pi}(1-\bar{n}) q(\hat{\pi})+\hat{\pi}(1-\underline{n})(1-q(\hat{\pi}))]\right\} d \mu_{o}\left(x_{o}\right) .
\end{gathered}
$$

The government balanced budget condition requires that total public expenditures in education (early education+college) equals the income tax revenue

$$
g+\kappa F=\tau Y
$$

with

$$
\kappa F=f \int \kappa\left(w h_{o}\right) g^{s}\left(x_{o}\right)[\bar{n} q(\hat{\pi})+\underline{n}(1-q(\hat{\pi}))] d \mu_{o}\left(s_{o}\right) .
$$

Finally, the resource constraint for the economy is given by,

$$
Y=F(H)=C_{y}+C_{o}+E+F+g
$$

where $C_{y}, C_{o}$, and $E$ are obtained by adding the corresponding policy rules across the entire population, and

$$
F=f \int g^{s}\left(x_{o}\right)[\bar{n} q(\hat{\pi})+\underline{n}(1-q(\hat{\pi}))] d \mu_{o}\left(x_{o}\right) .
$$

\subsection{Definition of Equilibrium}

A Stationary Recursive Competitive Equilibrium in this economy is a set of functions $V_{y}\left(x_{y}\right)$, $V_{o}\left(x_{o}\right), g^{c_{y}}\left(x_{y}\right), g^{e}\left(x_{y}\right), g^{c_{o}}\left(x_{o}, s, \theta\right), g^{h_{y}^{\prime}}\left(x_{o}, s, \theta\right), g^{s}\left(s_{o}\right), f^{H}$, price $w$, government expenditures in early education $g$, and time invariant distributions of young and old parents $\left(\mu_{y}, \mu_{o}\right)$ across states, such that: $(i)$ Given $w$ and $g$, young and adult parents solve their optimization problems and policy functions are optimal, (ii) Given $w, f^{H}$ maximizes firms profits, and (iii) Markets clear and the government budget is balanced. 


\section{$3 \quad$ Restricting the Economy}

In order to obtain numerical solutions for our model economy, we have to specify the relevant functional forms and calibrate parameter values. We do this to represent as close as possible relevant features the U.S. economy at the beginning of the nineties, in particular, the level and composition of expenditures in education, the disparity in college attainment and earnings, and the degree of intergenerational mobility. The benchmark economy is the basis in which we implement in the next section counterfactual experiments regarding the sources of persistence (innate abilities, early education, and college education) and the consequences of changes in government policy.

\subsection{Functional Forms}

We use a constant relative risk aversion utility function to describe preferences

$$
u(c)=\frac{c^{1-\sigma}-1}{1-\sigma},
$$

and a linear constant returns to scale production technology

$$
F(H)=A H
$$

We also choose the acquired ability (or early education) function,

$$
G(\pi, e+g)=\pi(e+g)^{\gamma}
$$

with $0<\gamma<1$. Notice that $g$ and $e$ are perfect substitutes in creating acquired ability. We do not interpret this as a claim that private and public schools are perfect substitutes. Instead, following Fernández and Rogerson (1996, 1998), we observe that public schools in different communities have different budgets because the common (federal and state) funding is complemented with local funding raised through income taxes. Therefore, public schools in richer communities receive more local funding. Our model should be interpreted as a extreme case in which each parent is a community and therefore chooses the amount of local (private) funding to public schools. In this sense, private funding $e$ and common funding $g$ are perfect substitutes. 
With respect to the college completion probability function, we assume

$$
q(\hat{\pi})=\min \left\{\psi_{0}(1+\hat{\pi})^{\psi_{1}}, 1\right\}
$$

with $\psi_{0}>0$ and $\psi_{1}>0$. This function is flexible enough to include as special cases a concave, linear or convex function. The shape of this function is very important for economic decisions in our model, since marginal changes in college completion probabilities are important determinants of the relative incentives for early investments in education between rich and poor parents. Our calibration procedure below allows for the shape of this function and other parameters to be determined by a set of calibration targets in the U.S. data.

Finally, we parameterize the government subsidy function to college education as

$$
\kappa\left(w h_{o}\right)=\max \left\{1-\kappa_{o} w h_{o}, 0\right\}
$$

this is, a linear decreasing function of parent's earnings. We choose a linear subsidy for its simplicity and because it has been often used in the Public Economics literature.

\subsection{Intergenerational Transmission of Abilities}

Innate abilities follow a first order discrete Markov process. We restrict the vector of states for $\pi$ and the elements in the transition matrix $\Phi$ in such a way that our process mimics the continuous $\mathrm{AR}(1)$ process,

$$
\log \left(\pi^{\prime}\right)=\rho \log (\pi)+\epsilon \quad \epsilon \sim N\left(0, \sigma_{\pi}^{2}\right)
$$

Tauchen (1986) provides a method to construct the mapping from a continuous AR(1) process to a first order Markov chain. Notice that, by construction, the resulting discrete process for $\pi$ has mean equal to one, satisfies $\pi_{\min }>0$, and converges to a log-normal stationary distribution,

$$
\pi \rightarrow \log N\left(0, \sigma_{\pi}^{2} /(1-\rho)\right)
$$

In this way, our Markov process for abilities depends only on two parameters: $\rho$ and $\sigma_{\pi}$. 


\subsection{Calibration}

Having restricted the model economy, we need to choose values for the following parameters: $\beta, \sigma$ (preferences), $A$ (technology), $\gamma, f, \bar{n}, \underline{n}, \bar{p}, \psi_{0}, \psi_{1}$ (education), $\xi$ (life-cycle), $\tau, \kappa_{o}$ (income tax and college subsidy) and $\sigma_{\pi}, \rho$ (stochastic process for innate abilities).

A few parameters have a direct empirical counterpart. With a length of a period in the model of 16 years, we set $\bar{n}=0.25$ and $\underline{n}=0.125$ corresponding to 4 years of college education and an average of 2 years in college for drop-outs (see Stinebrickner and Stinebrickner, 2001 and Manski and Wise, 1983). We set $\xi=1.10$ as the average wage of a male full-time worker 49-64 years old relative to a 33-48 years old, in both cases with college education, obtained for 1990 from the PSID. We normalize $A=1$ and choose $\beta=0.52$ (equivalent to an annual discount factor of 0.96). There is very little guidance on the value for the inter-temporal preference parameter, therefore we follow the real business cycle literature and use $\sigma=1.5$.

We choose an earnings premium for college students of $\bar{p}=1.5$. This number requires a brief discussion. In our model, $\bar{p}$ represents the lifetime earnings premium for an individual that completes college, relative to the same individual in the counterfactual situation of not attending college. This cannot be directly mapped into the rates of return for college education obtained from standard Mincer regressions, since these rates do not typically correct for the ability bias implied by the selection of individuals between college and noncollege choices. There is a large literature addressing this issue. We refer to the seminal paper by Willis and Rosen (1979) that, adjusting for selection in ability, finds a lifetime rate of return of attending college of $9.9 \%$ per year. Even though this number does not explicitly consider the completion premium, we consider it a conservative estimate of the return to college education, therefore $\bar{p}=\exp (0.099 \times 4)=1.5$.

It is also important to discuss the empirical counterpart of expenditures in education in our model. Total expenditures in early education $(e+g)$ in our model corresponds to the sum of public and private expenditures in primary and elementary education in the data. From the Statistical Abstract of the U.S. (1999) we find that expenditures in primary and elementary education represent $4.4 \%$ of GDP for 1990 and we use it as a target of our calibration procedure (see item 3 in the list below). From this number, we include as public expenditures in primary and elementary education ( $g$ in our model) only federal and state expenditures, adding up to $2.1 \%$ of GDP. Local government expenditures in early education

are imputed to $e$, since they vary across households according to the community where they live.

Using again data from the Statistical Abstract of the U.S. (1999), total college expen- 
ditures ( $F$ in our model) represent $2.8 \%$ of GDP in 1990. This is another target in our calibration procedure (see item 4 in the list below). Public expenditures account for $64 \%$ of total college expenditures, another target of our calibration (see item 5 in the list below). Adding public federal and state expenditures in early education and total government expenditures in college education, we obtain a share of public expenditures in education of $3.9 \%$ of GDP. In our model, this target determines directly the proportional tax rate on earnings $\tau=(g+\kappa F) / y=0.039$.

The remaining seven parameters are simultaneously calibrated to match the following observations for the U.S. economy (targets) with the corresponding endogenous variables in the model:

1. Fraction of non-college over total 33-48 years old workers of 0.54 (from PSID, 1990).

2. Fraction of college students that drop-out of 0.5 (from PSID, 1990).

3. Share of total expenditures in early education over GDP equal to $4.4 \%$ (see discussion above).

4. Share of total expenditures in college education over GDP equal to $2.8 \%$ (idem).

5. Fraction of public college expenditures over total college expenditures of $64 \%$ (idem).

6. Standard deviation of the log of permanent earnings across all workers equal to $0.6^{6}$ (from Mulligan, 1997) ${ }^{7}$.

7. Degree of intergenerational persistence of earnings of 0.4 (from Solon, 1992 and others, as reviewed in the introduction).

The calibration procedure involves solving a non-linear system of seven equations (one for each target) with seven unknowns (the value of the parameters $\psi_{0}, \psi_{1}, \gamma, f, \kappa_{0}, \sigma_{\pi}$, and $\rho$ ). Because solving the stationary equilibrium involves finding $g$ that is consistent with a

\footnotetext{
${ }^{6}$ The standard deviation of log earnings in the PSID is around 0.8. However, this is not the measure of disparity in earnings consistent with our model, since it includes temporary idiosyncratic earnings shocks, from which we abstract. The measure of permanent earnings in Mulligan (1997) uses 5-year averages to mitigate temporary shocks, reducing the disparity. Notice however that other authors, using different methodologies, have obtained even smaller disparities in permanent earnings. For example, Gottschalk and Moffitt (1994) obtain a standard deviation of the log of permanent earnings of 0.49 and Zimmerman (1992) decomposes $\log$ earnings into permanent and temporary components obtaining a standard deviation of 0.4. He finds that the permanent component of earnings accounts for $2 / 3$ of the cross-sectional variance.

${ }^{7}$ We thank Casey Mulligan for supplying the tabulations of Tables A1 and A2 (pages 252-253 in Mulligan, 1997) for the combined sample of Groups 1 and 2 and for the data in logs.
} 
balanced budget, our computational strategy looks for a fixed point of the equilibrium and calibration parameters at the same time ${ }^{8}$.

\section{Results for the Benchmark Economy}

We compute statistics for the benchmark economy as described in the previous section and compare them to the calibration targets. In this economy, investments in education account for half of the intergenerational persistence in earnings and one fourth of the cross-sectional inequality in permanent earnings.

\subsection{Calibration Targets}

The benchmark economy reproduces the calibration targets very well. Table 1 reports the results of the model along the dimensions specified in the previous section. In the benchmark economy, as in the data, the fraction of children enrolled in college is $46 \%$, but only half of these actually graduate from college. These results are obtained using a completion probability function that is almost linear in acquired abilities $\left(\psi_{1} \approx 1\right)$. The proportion of resources devoted to early education and college education are $4.4 \%$ and $3 \%$ of aggregate output in the model, while these are $4.4 \%$ and $2.8 \%$ of GDP in the data.

The implied elasticity of acquired ability with respect to expenditures in early education, $\gamma=0.24$, is in the range of values estimated in the empirical literature regarding human capital production functions ${ }^{9}$. The public share of college expenditures of $64 \%$ is matched exactly using a highly progressive subsidy, with slope $\kappa_{0}=0.38$.

Finally, the $\mathrm{AR}(1)$ process for abilities is calibrated to exactly match the standard deviation of the $\log (0.6)$ and the coefficient of intergenerational persistence (0.4) of permanent earnings in the data. We measure disparity in the model as the standard deviation of $\log \left(w h_{o}\right)$ across parents, and the degree of intergenerational persistence as the estimated $\hat{\beta}_{1}$ coefficient in the regression

$$
\log \left(w h_{y}^{\prime}\right)=\beta_{0}+\beta_{1} \log \left(w h_{o}\right)+\varepsilon
$$

\footnotetext{
${ }^{8} \mathrm{~A}$ brief description of the computational strategy is described in the appendix. A more detailed description of the computational algorithm is available from the authors upon request.

${ }^{9}$ Haley (1976) and Heckman (1975) estimates of this elasticity are between 0.4 and 0.6 using a broader definition of inputs in human capital production, while Card and Krueger (1996) find an elasticity of 0.1 to 0.2 using a narrower definition of inputs.
} 
using a simulated sample of parent-children pairs. Since the implied disparity and intergenerational persistence in innate abilities are around 0.4 and 0.2 , respectively, the model amplifies the effect of innate abilities in these two dimensions, that is, the model generates endogenously both disparity and persistence.

Table 1: Calibration of Benchmark Model

\begin{tabular}{||lcc|cc||}
\hline Target & Data & Model & Parameter & Value \\
\hline 1. Fraction of non-college & 0.54 & 0.54 & $\psi_{0}$ & 0.27 \\
2. Dropout rate & 0.50 & 0.50 & $\psi_{1}$ & 1.01 \\
3. Early education/GDP & 0.044 & 0.044 & $\gamma$ & 0.24 \\
4. College/GDP & 0.028 & 0.030 & $f$ & 0.75 \\
5. Public/total college & 0.64 & 0.64 & $\kappa_{0}$ & 0.38 \\
6. Std(log earnings) & 0.60 & 0.60 & $\sigma_{\pi}$ & 0.44 \\
7. Interg. persist. earnings & 0.40 & 0.40 & $\rho$ & 0.21 \\
\hline
\end{tabular}

\subsection{Policy Rules and Amplification Mechanisms}

The amplification mechanisms of the model can be easily observed in Figure 1. To construct this figure, we simulate the benchmark economy for a large number $(10,000)$ of parents drawn from the invariant distribution $\mu$. For each parent, we use the policy rules and random realizations of the completion shock to predict the level of education and human capital of the corresponding child. We then classify parents in earnings quintiles, and for each quintile we compute averages of children's innate ability, acquired ability, and human capital. Finally, for comparison purposes, we plot the average of these variables in each quintile relative to the first (bottom) quintile.

In Figure 1, innate abilities increase with parents earnings since a fraction of these abilities are inherited. However, the increase is small, only about $30 \%$ from the lowest to the top quintile. In the case of acquired abilities, the relation with parents earnings is much steeper, with an increase from the lowest to the top quintile of almost $90 \%$. This is entirely due to differences in investments in early education between rich and poor families, as shown in the corresponding policy function (see Figure 2). Since parents face severe borrowing constraints, only rich young parents can invest the efficient level of education, while poorer parents invest progressively less in their children's early education ${ }^{10}$. This mechanism is standard in theories of intergenerational mobility, for instance Becker (1993).

\footnotetext{
${ }^{10}$ This policy rule also displays a compensating effect of expenditures with respect to innate abilities.
} 
Coming back to Figure 1, there is a further increase in children's human capital of rich parents due to college education. As a result, children's human capital is $110 \%$ higher for the top earnings quintile compared to the lowest quintile, about 3.5 times the comparable difference in innate abilities. The policy rule for college enrollment (see Figure 3) shows that high acquired ability children, mostly coming from rich households, go to college and further increase their human capital. Low acquired ability children, coming out mostly from poor households, for the same reason, do not go to college. The exception are low ability children of very rich parents, but this is unlikely to be important quantitatively since the mass of individuals in this situation (given by the invariant distribution) is very small. Average acquired ability children go to college if their parents are rich enough to pay for college education, or poor enough to receive almost full government subsidy ${ }^{11}$.

The resulting average college enrollment and completion rates by parent's earnings quintile are plotted in the top panel of Figure 4. We observe that rich parents are not only more likely to send their children to college, but also these children exhibit higher graduation rates. This property of college enrolment and completion rates across earnings groups is exactly what we observe in the data. The bottom panel of Figure 4 shows these statistics from the data, computed by Manski (1992) using data from the U.S. Current Population Survey. Notice, however, that this property of the college enrolment and completion rates across earnings groups is not a direct result of our calibration procedure, but an endogenous consequence of the incentives implied by the college completion probabilities and the progressive college subsidy scheme.

An alternative way of illustrating the source of inequality and persistence in the model is to look at these variables at each stage of life in our model: when born, before college, and after college. Table 2 reports inequality and persistence at these stages of life in the model. Two striking results emerge. First, endogenous earnings persistence happens at the early education stage, in fact, college reduces persistence in the benchmark economy. Second, most of the inequality in earnings generated by endogenous investments in education is due to college outcomes. Therefore, early education is central to understanding persistence in

Parents invest more in low ability children because the return of raising their acquired ability is higher. Still, rich parents are more able to compensate low ability children than poor parents.

${ }^{11}$ Both extremes are likely to highlight two sources of inefficiencies in the benchmark economy. First, old parents might also be borrowed constrained, so their decision of sending or not their children to college depends on their earnings. Second, a highly progressive college subsidy might induce poor parents to send their children to college independently on their acquired ability and hence on their chances of graduating. The importance of these distortions for the amplification effect of college education is investigated in the experiments in the next section. 
earnings while college education accounts for a large portion of inequality. This role of early and college education in persistence and inequality of earnings are central to understanding public policy implications discussed below.

Table 2: Inequality and Persistence in the Benchmark Economy

\begin{tabular}{||l|ccc||}
\hline & Innate Ability & Acquired Ability & Human Capital \\
\hline Std $(\log \mathrm{x})$ & 0.45 & 0.49 & 0.60 \\
Int. Correlation & 0.21 & 0.42 & 0.40 \\
\hline
\end{tabular}

\subsection{Intergenerational Persistence}

While the model reproduces the degree of intergenerational persistence of earnings of 0.4 , we would like to decompose this persistence into exogenous and endogenous components. The exogenous ability persistence needed to account of the observed correlation of earnings across generations is $\rho=0.21$, that is, roughly half of the intergenerational persistence in earnings is accounted for by endogenous educational investments. This doesn't mean that a model with no innate persistence in abilities between parents and children would generate a persistence of earnings of 0.19 , since the interaction between innate abilities and educational investments could potentially increase or decrease this number. In the next section, we report an experiment with zero innate ability persistence $(\rho=0)$ and provide a definite decomposition.

We calculate the degree of intergenerational persistence in other economic variables using simulations of the benchmark economy. These are reported in the first column of Table 4. First, the intergenerational correlation of household consumption between parents and children when adults is 0.66 in the model. Mulligan reports a coefficient of intergenerational persistence of consumption of 0.68. Second, we compute the intergenerational persistence of educational attainment. In the benchmark economy this number is 0.2. Mulligan (1999) reports an intergenerational correlation of schooling for the U.S. economy around 0.29. In the experiments below, we show that the correlation of educational attainment between parents and their children in the model is due to a combination of intergenerational innate ability persistence and early schooling investments. Keane and Wolpin (2001) obtain similar results in their structural estimation of the U.S economy. 


\subsection{Cross-Sectional Disparity}

Table 4 reports additional statistics regarding cross-sectional disparity. As another illustration of the amplification effect of the model, we verify that the initial disparity in abilities (0.45), measured as the standard deviation of the log, increase as a result of differences in educational investments to 0.49 in acquired abilities (due to early education), and to 0.6 in human capital or earnings (due to college education).

The average wage of college graduates, relative to non college workers, is 2.56 in the benchmark economy. This number is much higher than the college premium $\bar{p}=1.5$, due to positive selection in abilities resulting from the endogeneity of college enrollment decisions: on average, college graduates have more acquired ability than non-college workers, so they would have earned more even if not attending college. The average wage of college dropouts relative to non-college workers is 1.76 , entirely due to the selection effect.

We compute similar statistics using a sample of 33-48 year-old workers from the 1990 PSID, and obtain an average relative wage of 2.33 for those which completed college and 1.41 for college dropouts, with respect to workers without any college education. These numbers are lower than in our model, but there are at least two reasons why this should be the case. First, workers with college education have steeper age-earnings profiles, so the lifetime premium should be higher than our estimate from the data. Second, our model abstracts from a comparative advantage mechanism, in which low ability individuals perform better in low skill jobs that require no college education. Including this mechanism would reduce the wage premia in the benchmark economy.

Our model has two important limitations. First, we do not have financial assets that allow for inter-temporal or intergenerational consumption smoothing. Second, the model does not include any post-college idiosyncratic earnings shocks. Both are important issues from which we abstract. As a result, we obtain implausibly large correlations between earnings and education, and between earnings and consumption (see again the first column in Table 4). Adding these features would certainly make the implications of the model closer to the data in these dimensions.

\section{Sources of Persistence}

What are the sources of intergenerational persistence in our model? In this section, we illustrate the role of key features of the environment by calibrating alternative specifications of the benchmark economy. We consider three alternative calibrations: no innate ability 
Table 3: Calibrated Parameter Values in Different Economies

\begin{tabular}{||c|c|ccc||}
\hline & & No Innate & No Early & No College \\
Parameter & Benchmark & Persistence & Education & Education \\
\hline$\psi_{0}$ & 0.27 & 0.27 & 0.38 & - \\
$\psi_{1}$ & 1.01 & 1.01 & 0.36 & - \\
$\gamma$ & 0.24 & 0.24 & 0.00 & 0.27 \\
$f$ & 0.75 & 0.69 & 1.52 & - \\
$\kappa_{0}$ & 0.38 & 0.39 & 0.33 & - \\
$\sigma_{\pi}$ & 0.44 & 0.48 & 0.54 & 0.55 \\
$\rho$ & 0.21 & 0.00 & 0.21 & 0.21 \\
\hline
\end{tabular}

persistence, no early education, and no college education. Our most important finding in this section is that early education is a fundamental component of earnings persistence.

\subsection{No Innate Ability Persistence $(\rho=0)$}

In this version of the economy, we assume no intergenerational persistence of innate ability $(\rho=0)$. We calibrate the economy to the same targets as in the benchmark economy, except the intergenerational correlation of earnings. The parameter values resulting from this calibration are reported in Table 3 along with parameter values for the benchmark economy and other experiments. No ability persistence is a central feature of the theory in Loury (1981) and the quantitative theory in Caucutt and Kumar (2001).

Persistence Table 4 reports the results of the experiment. The main reuslt is the decrease in the intergenerational persistence of earnings compared to the benchmark economy, from 0.4 to 0.24 . Notice that the intergenerational persistence generated by endogenous human capital investments in the model is slightly larger than the one generated by the same component of investments in the presence of innate ability correlation between parents and children. The reason is that with no correlation of innate abilities between parents and children, borrowing constraints to educational investments become more severe, that is, it is more likely that low earnings parents have high ability children and therefore are limited in the amount of resources that can be allocated to education.

The intergenerational correlation of educational attainment falls to virtually zero, while it is 0.20 in the benchmark economy. This is in contrast to the results in Caucutt and Kumar (2001). In their model, the correlation of educational attainment is generated by the exogenous dropout probabilities, by assuming that children of college educated parents 
Table 4: Sources of Intergenerational Persistence of Earnings

\begin{tabular}{|c|c|c|c|c|}
\hline & Benchmark & $\begin{array}{l}\text { No Innate } \\
\text { Persistence } \\
\quad(\rho=0)\end{array}$ & $\begin{array}{l}\text { No Early } \\
\text { Education } \\
(\gamma=0)\end{array}$ & $\begin{array}{l}\text { No College } \\
\text { Education } \\
(f \rightarrow \infty)\end{array}$ \\
\hline $\begin{array}{l}\text { Intergenerational persistence } \\
\text { - Earnings } \\
\text { - Educational attainment } \\
\text { - Consumption }\end{array}$ & $\begin{array}{l}0.40 \\
0.20 \\
0.66\end{array}$ & $\begin{array}{l}0.24 \\
-.02 \\
0.55\end{array}$ & $\begin{array}{l}0.16 \\
-.05 \\
0.55\end{array}$ & $\begin{array}{l}0.41 \\
1.00 \\
0.69\end{array}$ \\
\hline $\begin{array}{l}\text { Cross-sectional disparity } \\
\quad \text { - Std(log innate abilities }) \\
\text { - Std(log acquired abilities }) \\
\text { - Std(log earnings })\end{array}$ & $\begin{array}{l}0.45 \\
0.49 \\
0.60\end{array}$ & $\begin{array}{l}0.48 \\
0.50 \\
0.60\end{array}$ & $\begin{array}{l}0.55 \\
0.55 \\
0.60\end{array}$ & $\begin{array}{l}0.57 \\
0.60 \\
0.60\end{array}$ \\
\hline $\begin{array}{l}\text { Cross-sectional correlation } \\
\text { - Log earnings/education } \\
\text { - Log earnings/consumption }\end{array}$ & $\begin{array}{l}0.85 \\
0.91\end{array}$ & $\begin{array}{l}0.81 \\
0.87\end{array}$ & $\begin{array}{l}0.47 \\
0.81\end{array}$ & $\begin{array}{c}- \\
0.85\end{array}$ \\
\hline $\begin{array}{l}\text { Average wage premium } \\
\text { - College/non-college } \\
\text { - Dropouts/non-college }\end{array}$ & $\begin{array}{l}2.56 \\
1.76\end{array}$ & $\begin{array}{l}2.45 \\
1.64\end{array}$ & $\begin{array}{l}1.49 \\
1.02\end{array}$ & - \\
\hline
\end{tabular}

are less likely to dropout. With endogenous dropout probabilities, innate ability correlation is important for educational attainment persistence given the risk of college completion. However, innate ability correlation is not enough. In the next experiment, we show that the lack of educational attainment persistence occurs when innate abilities are correlated but there is no early education, hence, both early education and innate ability persistence are important for generating the observed positive intergenerational persistence in educational attainment in our model.

Discussion Figure 5 shows the sources of persistence in this model. While innate ability is not systematically related with parent's earnings groups, acquired ability and human capital are strongly related with parent's earnings. Notice that most of the differences show up right away at the early education level, and the college education adds little to this disparity, perhaps most in the highest earnings group. Another implication of the model without innate ability persistence is the behavior of college enrollment and completion by earnings groups. Figure 6 shows that enrollment follows an inverted U-shape with parent's earnings. That is, no ability persistence implies that more individuals from poor families are talented and these individuals tend to enroll in college. Notice however, that this implication is inconsistent with the data. 


\subsection{No Early Education $(\gamma=0)$}

We modify the benchmark economy by eliminating early education. The purpose of this experiment is to evaluate the role of early and college education in generating outcomes in the benchmark economy. We implement the no early education economy by setting the return to resources in early education to zero $(\gamma=0)$. Given this assumption, both private and public expenditures in early education are equal to zero, implying that acquired and innate ability of each individual are equal at the college stage.

We calibrate the economy to match the following targets: fraction of non-college, fraction of dropouts, college expenditures over GDP (private and public), and the standard deviation of log earnings. We reduce the extent of the government in the economy by considering only the resources allocated to higher education. The variance of innate ability necessary to reproduce the variance in earnings is higher in the absence of early education. Another important implication of the calibration is that the parameters related to college completion $\left(\psi_{0}\right.$ and $\left.\psi_{1}\right)$ imply a much flatter relationship with acquired ability than the one implied by the benchmark calibration. A summary of the parameter values needed to match the calibration targets are reported in Table 3. The results of the experiment are summarized in Table 4.

Persistence The model without early education generates a relatively low persistence of earnings across generations, 0.16. Notice that the persistence is even lower than the exogenous persistence introduced in the model through innate ability, 0.20 . Therefore, college education serves as an equalizing force in the economy. This is due to the the progressivity of the college subsidy, since poor families face a lower cost of attending college; and the risk of college completion. As a result, college enrollment rate is decreasing in parents' earnings (see Figure 6), and there is almost no correlation in educational attainment across generations.

Discussion The correlation between earnings and education is much lower in this version of the model than in the benchmark economy, 0.47 and 0.85 respectively. Also the absence of early education substantially reduces the wage premium with respect to the benchmark economy. With a college completion probability that depends on acquired ability (innate ability in this case), college education alone does not generate an intergenerational correlation of educational attainment even in the presence of innate ability correlation. Again, the role of early education and innate ability persistence on acquired ability and its impact on college completion are important in generating the intergenerational correlation of 
educational attainment.

\subsection{No College Education $(f \rightarrow \infty)$}

We implement the economy with no college education by setting the fixed cost $f$ to a level where no individual finds it optimal to obtain college education. In the calibration we set the value of government resources devoted to education to correspond only to primary and elementary education. The economy is calibrated to match the following targets: the fraction of non-college, fraction of dropouts, early education expenditures over GDP, and the standard deviation of log earnings. The parameters needed to match these targets are reported in Table 3 and the results from this economy in Table 4.

Persistence Compared to the benchmark economy, the model with no college education generates a similar, if not higher, correlation of earnings across generations. This result supports the view that progressive, need-based, college subsidies have a positive, although limited, impact on earnings mobility.

Discussion The results of the model without college education are similar to those for the benchmark economy, with the only exception being that most earnings inequality is generated exogenously by the inequality in innate ability. Therefore, college education is an important component of earnings inequality in the model. Another way of illustrating this result is that in the benchmark economy, $1 / 4$ of the earnings inequality is due to endogenous investments in education (where $70 \%$ of this due to college education) while in the non-college economy only $1 / 20$ is generated by endogenous investments in education.

\section{Policy Experiments}

Our theory of intergenerational earnings inequality with early and college education is suited to study the implications of government policies towards education. First, we analyze the effect of a $20 \%$ increase in total government expenditures in education if $(i)$ the increase is devoted to early education, or $(i i)$ if the additional resources are allocated to college subsidies. We show that the first policy is more effective than the second in reducing the intergenerational persistence of earnings. Finally, we consider a modification of the progressive (need-based) college subsidy to a flat subsidy, and find that such a change would 
Table 5: Policy Experiments

\begin{tabular}{||l|c|cc|c||}
\hline & Benchmark & $\begin{array}{c}\text { Increase } \\
\text { Early } \\
\text { Expendit. }\end{array}$ & $\begin{array}{c}\text { Increase } \\
\text { College } \\
\text { Subsidy }\end{array}$ & $\begin{array}{c}\text { Flat } \\
\text { College } \\
\text { Subsidy }\end{array}$ \\
\hline Intergenerational persistence & 0.40 & 0.34 & 0.40 & 0.48 \\
$\quad$ - Earnings & 0.20 & 0.10 & 0.17 & 0.53 \\
- Educational attainment & 0.66 & 0.63 & 0.66 & 0.68 \\
- Consumption & & & & \\
Cross-sectional disparity & 0.45 & 0.45 & 0.45 & 0.45 \\
- Std(log innate abilities) & 0.49 & 0.49 & 0.49 & 0.48 \\
- Std(log acquired abilities) & 0.60 & 0.59 & 0.59 & 0.58 \\
- Std(log earnings) & & & & \\
Cross-sectional correlation & 0.88 & 0.86 & 0.85 & 0.77 \\
- Log earnings/education & 0.88 & 0.89 & 0.90 & 0.90 \\
- Log earnings/consumption & & & & \\
Average wage premium & 2.56 & 2.51 & 2.62 & 2.29 \\
- College/non-college & 1.76 & 1.73 & 1.78 & 1.54 \\
- Drop outs/non-college & & & & \\
\hline Expenditures (percent of GDP) & 2.31 & 1.77 & 2.30 & 2.26 \\
- Private early education & 1.98 & 2.80 & 1.98 & 1.99 \\
- Public early education & 1.10 & 1.05 & 1.27 & 0.82 \\
- Private college education & 1.92 & 1.92 & 2.66 & 1.91 \\
- Public college education & & & & \\
\hline Other Aggregate Statistics & 0.46 & 0.47 & 0.63 & 0.41 \\
- College enrolment & 0.50 & 0.49 & 0.52 & 0.50 \\
- Dropout rate & 2.15 & 2.22 & 2.20 & 2.11 \\
- Aggregate human capital (GDP) & 1.99 & 2.05 & 2.02 & 1.96 \\
- Aggregate consumption & \multicolumn{2}{|c||}{}
\end{tabular}

considerably increase persistence. Notice that the three policies implicitly assume that the government cannot observe the ability of children, only parents' earnings.

\subsection{Increase in Early Education Expenditures}

In the first experiment, we increase the share of total public resources devoted to education over GDP by $20 \%$, to $\tau=0.047$, keeping constant the share of expenditures in college education over GDP $(\kappa F / y=0.0192)$. As a result, in equilibrium, public resources devoted to early education increase from $1.98 \%$ to $2.8 \%$ of GDP. The results of this experiment compared with the benchmark economy are reported in Table 5. 
Persistence The intergenerational persistence of earnings falls by a sizable amount, from 0.4 in the benchmark economy to 0.34 . The persistence in educational attainment and consumption are also reduced. As expected, this policy mitigates budget constraint problems for poor families that need it the most, that is, when investing in the early education of their children. Moreover, since the subsidy is lump-sum and public and private expenditures in education are perfect substitutes in production, there is a large substitution effect. The increase in public early education expenditures is associated with a large decrease in private expenditures, equalizing the quality of early education across children. A need-based early education subsidy would be even more effective at mitigating credit constraints at this investment stage.

College Enrollment and Completion The policy produces a small increase in aggregate college enrollment and a small decrease in the dropout rate, due again to the substitution effect. Since parents substitute private with public expenditures in early education, the effect of this policy on the dropout probabilities is considerably attenuated. By earnings groups, the policy makes college enrollment less steep, since the quality of early education of poor children increases and their dropout rate falls. Figures 6 and 7 compare college enrollment and dropout rates by income groups under this policy and the benchmark economy.

Output, Consumption, and Efficiency As expected, this policy increases aggregate human capital and therefore aggregate output. Perhaps surprisingly, it also increases aggregate consumption, this is, output net education costs. Comparing the steady states of the benchmark economy and the economy with higher government expenditures in early education, the average parent consumes more in the latter economy. This is not a definite welfare calculation of the benefits of such policy, since we do not compute the transition between steady states. Nevertheless, the steady state comparison is interesting since it provides a quantitative assessment of two contradictory effects. First, the increase in government expenditures mitigates the distortion introduced by borrowing constraints to investments in early education by poor parents, increasing efficiency. Second, this lump-sum subsidy also benefits rich parents with low ability children, that receive a higher than optimal level of education. The numerical experiment shows that, relative to the benchmark calibration, the first effect dominates and efficiency is enhanced through this policy.

Discussion These policy implications of the model are consistent with the available crosscountry evidence. Both Canada and Sweden have lower measures of inequality and intergen- 
erational persistence than the U.S. (see Corak and Heisz, 1999 for Canada and Björklund and Jäntti, 1997 for Sweden). Differently than in the U.S., where a large proportion of early educational investments are related to parent's earnings, Canada and Sweden have early educational systems that are mostly funded at the federal level, reducing the disparity in school expenditures.

\subsection{Increase in College Subsidies}

In this experiment, we increase the aggregate share of public resources devoted to education over GDP by $20 \%$, that is a change in the tax rate, $\tau$, from 0.039 in the benchmark economy to 0.047. We increase aggregate expenditures while keeping constant the share of expenditures in early education over GDP $(g / y=0.0198)$ and the the progressiveness of the college subsidy, $\kappa_{o}=0.38$. Under these assumptions, the increase in expenditures amounts to choosing a college subsidy, $\kappa_{1}$, in order to reproduce a share of public resources devoted to college education over GDP of $2.66 \%$, where the college subsidy function is given by,

$$
\kappa\left(w h_{o}\right)=\min \left\{\max \left\{\kappa_{1}-\kappa_{o} w h_{o}, 0\right\}, 1\right\} .
$$

The resulting parameter value is $\kappa_{1}=1.025$.

Persistence The third column of Table 5 reports the result of the experiment. The intergenerational persistence of earnings and consumption is the same as in the benchmark economy, while the persistence in educational attainment falls by a small amount. This policy fails in reducing persistence because it benefits poor parents too late, when the early education decisions have already been made.

College Enrollment and Completion The increase in college subsidy generates an increase in aggregate college enrollment. Figure 6 shows that this increase is larger for poor families, due to the progressivity of the subsidy. However, the aggregate drop-out rate also increases. Poor families are still constrained at the early education level, so the average acquired ability of their children is still low. The increase in the subsidy makes them to attend college, but does not change their high dropout probability (see Figure 7).

Output, Consumption, and Efficiency The policy also produces an increase in aggregate human capital (output) and aggregate consumption, but smaller in size to the previous 
policy. The experiment confirms that borrowing constraints (and the distortions induced by them) are more important at the early educational stage.

\subsection{Flat College Subsidy}

In the last experiment, we move from progressive subsidy considered in the calibration of our benchmark economy to a flat college subsidy, independent of the individual's family earnings. We assume a college subsidy function $\kappa=\kappa_{0}$ and choose $\kappa_{0}$ to match the resources allocated by the government to college. In this sense, this is an expenditure-neutral experiment. We keep all other parameter values of the benchmark economy the same.

Persistence A flat college subsidy produces a significant increase in the intergenerational persistence of earnings and educational attainment, as shown in the last column of Table 5. The reason is that it increases the incentives to invest in early education for children of richer families who later on go to college at a higher subsidized rate than in a progressive subsidy. A higher proportion of the college subsidy go to children of higher earnings families, worsening the borrowing constraint of poor families at the college level. Hence, poor families reduce their investment in early education.

College Enrolment and Completion A flat college subsidy produces the same dropout rate as in the benchmark economy, but it reduces slightly college attendance. This is the result of two opposing effects across family earnings: the proportion of children of poor families attending college falls while the proportion of children from rich families increases. The steepness of the college enrollment profile across earnings groups, documented in Figure 6 , is much higher than in the benchmark economy. Regarding college completion rates by earnings groups, Figure 7 reports the differences between a flat and a progressive subsidy: under the flat subsidy completion rates are decreasing in earnings groups, while there are increasing under the progressive subsidy. This is, with a flat subsidy poor children going to college are more positively selected, but the opposite occurs with rich children. These two effects cancel out at the aggregate dropout rate.

Output, Consumption, and Efficiency Under a flat subsidy, aggregate human capital (output) and consumption falls relative to the benchmark economy. Again, this is due to the fact that the flat subsidy aggravates the budget constraint for poor families with able children. Notice that the optimal policy would eliminate all credit constraints, and 
allocations would be entirely due to innate ability considerations. A progressive subsidy achieves this objective more than a flat subsidy since it allocates resources where they are needed the most, that is, among families with able children who face credit restrictions to finance educational expenditures.

\section{Conclusions}

We develop a model of early human capital investments and college education that is suited to study the interaction of ability, investment opportunities, and luck in determining disparity and persistence in education and earnings. We find that differences in the quality of early education is the most important component of earnings persistence across generations.

In this framework we study government policies often motivated to promote equal opportunities. We find that policies that reduce the extent of credit constraints at the early level to be the most productive in terms of reducing persistence while at the same time, increasing aggregate output and consumption. Policies targeted at the college level would have a limited impact on persistence. However, a need-based college subsidy system is important to provide the right incentives for poor families to invest in early education.

There are three main limitations of our model. First, we abstract from any other asset accumulation different from human capital. Second, we abstract from features different from human capital that may determine earnings, in particular, we abstract from permanent idiosyncratic earnings shocks. Third, we abstract from many other dimensions of early human capital formation that may be important, like parent's time in early development, peer group effects and neighborhood effects, among others. These extensions are likely to enhance our understanding of the channels addressed in this paper, the quantitative implications of the theory, and the policy recommendations derived from it. Our simplified theory of intergenerational earnings persistence motivates an important role of human capital and policy in generating inequality and persistence in earnings, and these extensions are natural steps for further research. 


\section{A Computing a Stationary Recursive Equilibrium}

The production function used in our model implies that the wage rate is equal to the technology parameter $A$. We normalize this price to one. Therefore, the computational task amounts to finding the value functions for young and old parents and the associated policy functions, for a given value of $g$, use these and the exogenous process for the stochastic components of the model to compute the associated invariant distribution of agents across states, and calculate the implied level of expenditures $g$ that balance the government budget. Therefore, the algorithm includes an outer loop that involves finding the equilibrium value of $g$, plus the values of the seven parameters calibrated simultaneously. Given government expenditures, an inner loop finds value functions and the invariant distribution by guessing initial values and applying successive approximations until reaching the fixed point. The steps are as follows:

1. Make initial guesses for value function of old adults, $V_{o}^{i=0, j=0}$ and $g^{i}$

2. Given $w, g$, and $V_{o}^{i, j}$, obtain $V_{y}^{i, j+1}$ from young parent's problem and compute the corresponding policy functions;

3. Given $w$, and $V_{y}^{i, j+1}$, obtain $V_{o}^{i, j+1}$ from old parent's problem and compute the corresponding policy functions;

4. Check for convergence of value function by comparing $V_{o}^{i, j}$ and $V_{o}^{i, j+1}$. If convergence criteria is satisfied then go to the next step, otherwise iterate from step (2) until convergence;

5. Guess a $\mu_{y}$ and use the optimal policy functions and law of motion for the shocks to obtain the invariant distribution $\left(\mu_{o}\right)$ and then $\mu_{y}^{\prime}$ both implied by the operator $T$; continue until convergence of $\mu_{y}$ and

6. Using the invariant distribution and optimal policy functions, compute $g^{i+1}$ by imposing the budget constraint of the government, and compare with $g^{i}$. Iterate from step (2) until convergence is achieved. 


\section{References}

[1] Ayagari, S. Rao, Jeremy Greenwood, and Ananth Seshadri. 2001. "Efficient Investment in Children." Journal of Economic Theory, 102(2): 290-321.

[2] Aiyagari, S. Rao, Jeremy Greenwood, and Nezih Guner. 2000. "On the State of the Union." Journal of Political Economy, 108(2): 213-244.

[3] Becker, G. and N. Tomes. 1979. "An Equilibrium Theory of the Distribution of Income and Intergenerational Mobility." Journal of Political Economy, 87(6): 1153-89.

[4] Becker, Gary. 1993. A Treatise on the Family. Boston: Harvard University Press.

[5] Björklund, Anders and Markus Jäntti. 1997. "Intergenerational Income Mobility in Sweden Compared to the United States." American Economic Review, 87(5): 10091018.

[6] Card, David and Alan Krueger. 1996. "School Resources and Students Outcomes: An Overview of the Literature and New Evidence from North and South Carolina." Journal of Economic Perspectives, 10(4): 31-50.

[7] Castañeda, Ana, Javier Díaz-Giménez, and José-Víctor Ríos-Rull. 2002. "Accounting for Earnings and Wealth Inequality." Journal of Political Economy, forthcoming.

[8] Caucutt, E. M. and K. Kumar. 2000. "Higher Education Subsidies and Heterogeneity: A Dynamic Analyisis" Journal of Economic Dyanamics and Control, forthcoming.

[9] Corak, Miles and Andrew Heisz. 1999. "The Intergenerational Earnings and Income Mobility of Canadian Men," Journal of Human Resoruces, 34(3): 504-533.

[10] Currie, Janet and Duncan Thomas. 1999. "Early Test Scores, Socioeconomic Status, and Future Outcomes." National Bureau of Economic Research Working Paper 6943.

[11] Erosa, Andrés and Tatyana Koreshkova. 2001. "Progressive Taxation in a Dynastic Model of Human Capital." Manuscript. University of Western Ontario.

[12] Fernández R. and R. Rogerson. 1996. "Income Distribution, Communities, and the Quality of Public Education." Quarterly Journal of Economics, 111: 135-164. 
[13] Fernández R. and R. Rogerson. 1998. "Public Education and Income Distribution: A Dynamic Quantitative Evaluation of Education-Finance Reform." American Economic Review, 88(4): 813-833.

[14] Fernández R. and R. Rogerson. 2001. "Sorting and Long-Run Inequality." Quarterly Journal of Economics, 116(4): 1305-1341.

[15] Gottschalk, P. and R. Moffitt. 1994. "The Growth of Earnings Instability in the U.S. Labor Market," Brookings Papers on Economic Activity, 2, 217-72.

[16] Haley, William. 1976. "Estimation of the Earnings Profile from Optimal Human Capital Accumulation." Econometrica, 44(6): 1223-38.

[17] Heckman, James. 1975. "Estimates of a Human Capital Production Function Embeded in a Life-Cycle of Labor Supply," in Household Production and Consumption, ed. N. Terleckyj, Columbia University Press, New York.

[18] Heckman, James. 2000. "Policies to Foster Human Capital." Research in Economics, 54: $3-56$.

[19] Keane, Michael and Kenneth Wolpin. 1997. "The Career Decisions of Young Men." Journal of Political Economy, 105(3): 473-522.

[20] Keane, Michael and Kenneth Wolpin. 2001. "The Effect of Parental Transfers and Borrowing Constraints on Educational Attaintment." International Economic Review, 42(4): 1051-1103.

[21] Knowles, J. 1999. "Can Parental Decisions Explain US Income Inequality?" Manuscript. University of Pennsylvania.

[22] Loury, G. 1981. "Intergenerational Transfers and the Distribution of Earnings." Econometrica, 49: 843-67.

[23] Manski, Charles F. 1992. "Parental Income and College Opportunity". Report Series, Democratic Study Center.

[24] Manski, C. and D. Wise. 1983. College Choice in America. Chicago: University of Chicago Press.

[25] Mulligan, C. 1997. Parental Priorities and Economic Inequality. Chicago: University of Chicago Press. 
[26] Mulligan, Casey. 1999. "Galton versus the Human Capital Approach to Inheritance". Journal of Political Economy, 107(6): S184-S224.

[27] Neal, D. and W. Johnson. 1996. "The Role of Pre-Market Factors in Black-White Wage Differences." Journal of Political Economy, 104(5): 869-895.

[28] Regalía, Ferdinando and José-Víctor Ríos-Rull. 1999. "What Accounts for the Increase in Single Households and the Stability in Fertility?" Manuscript. University of Pennsylvania.

[29] Sacerdote, Bruce. 2002. "The Nature and Nurture of Economic Outcomes." American Economic Review, 92(2): 344-348.

[30] Solon, G. 2000. "Intergenerational Mobility in the Labor Market." in Handbook of Labor Economics, 3A: 1761-1800.

[31] Statistical Abstract of the United States. 1999. U.S. Census Bureau.

[32] Stinebrickner, Todd and Ralph Stinebrickner. 2001. "The Underlying Relationship between Family Income and Schooling Attainment: Evidence from a Liberal Arts College with a Full Tuition Subsidy Program." Manuscript. University of Western Ontario.

[33] Stokey, N. 1999. "Shirtsleeves to Shirtsleeves: The Economics of Social Mobility." in Frontiers of Research in Economic Theory. Jacobs, Kadar, and Kamien Editors. Cambridge University Press. New York.

[34] Tauchen, G. 1986. "Finite State Markov Chain Approximations to Univariate and Vector Autoregressions". Economic Letters, 20: 177-181.

[35] Willis, R. and S. Rosen. 1979. "Education and Self-Selection". Journal of Political Economy, 87(5): S7-S36.

[36] Zimmerman, D. 1992. "Regression Toward Mediocrity in Economic Stature." American Economic Review, 82(3): 409-29. 
Figure 1: Ability and Human Capital by Parent's Earnings Quintile

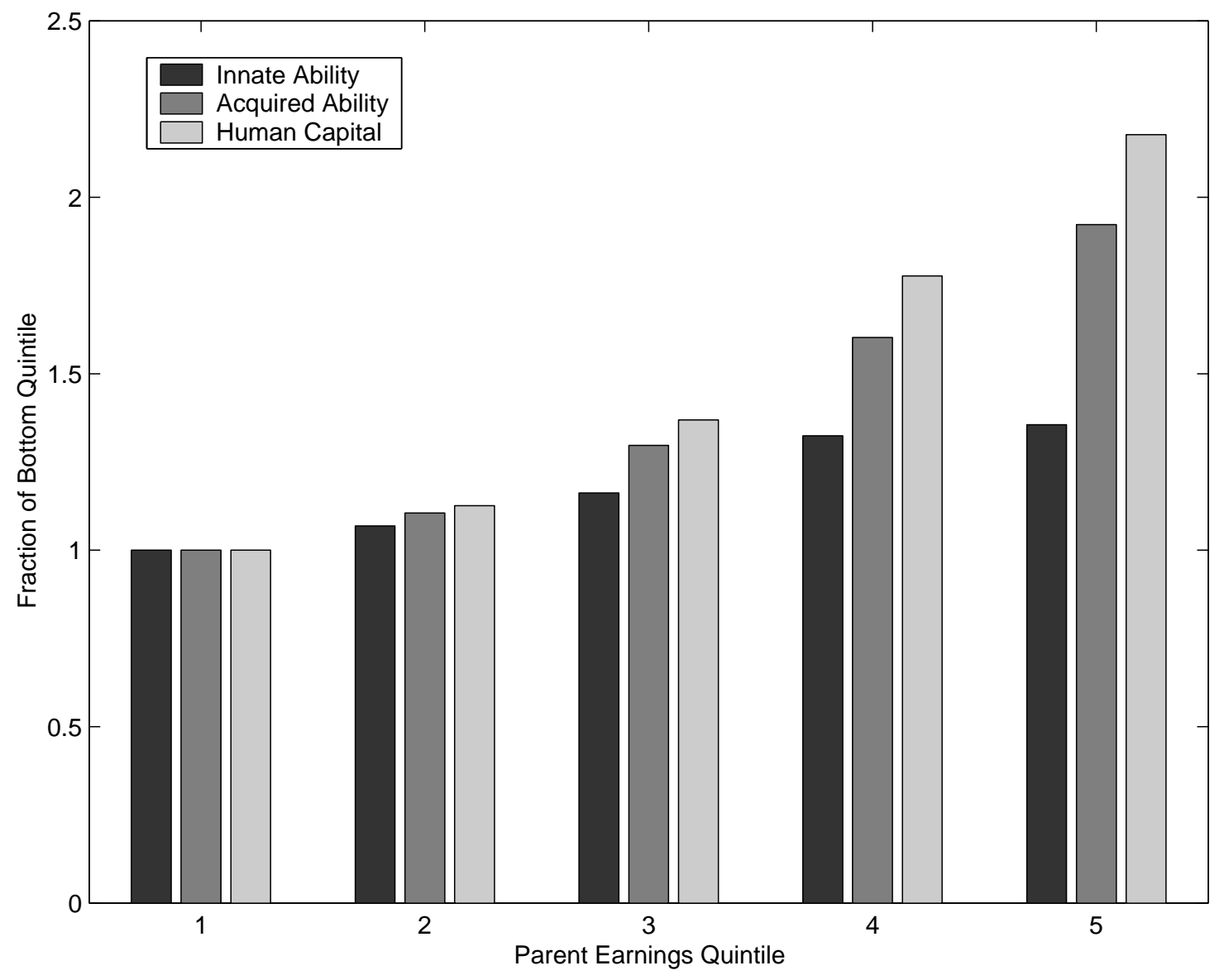


Figure 2: Education Early Investment Policy

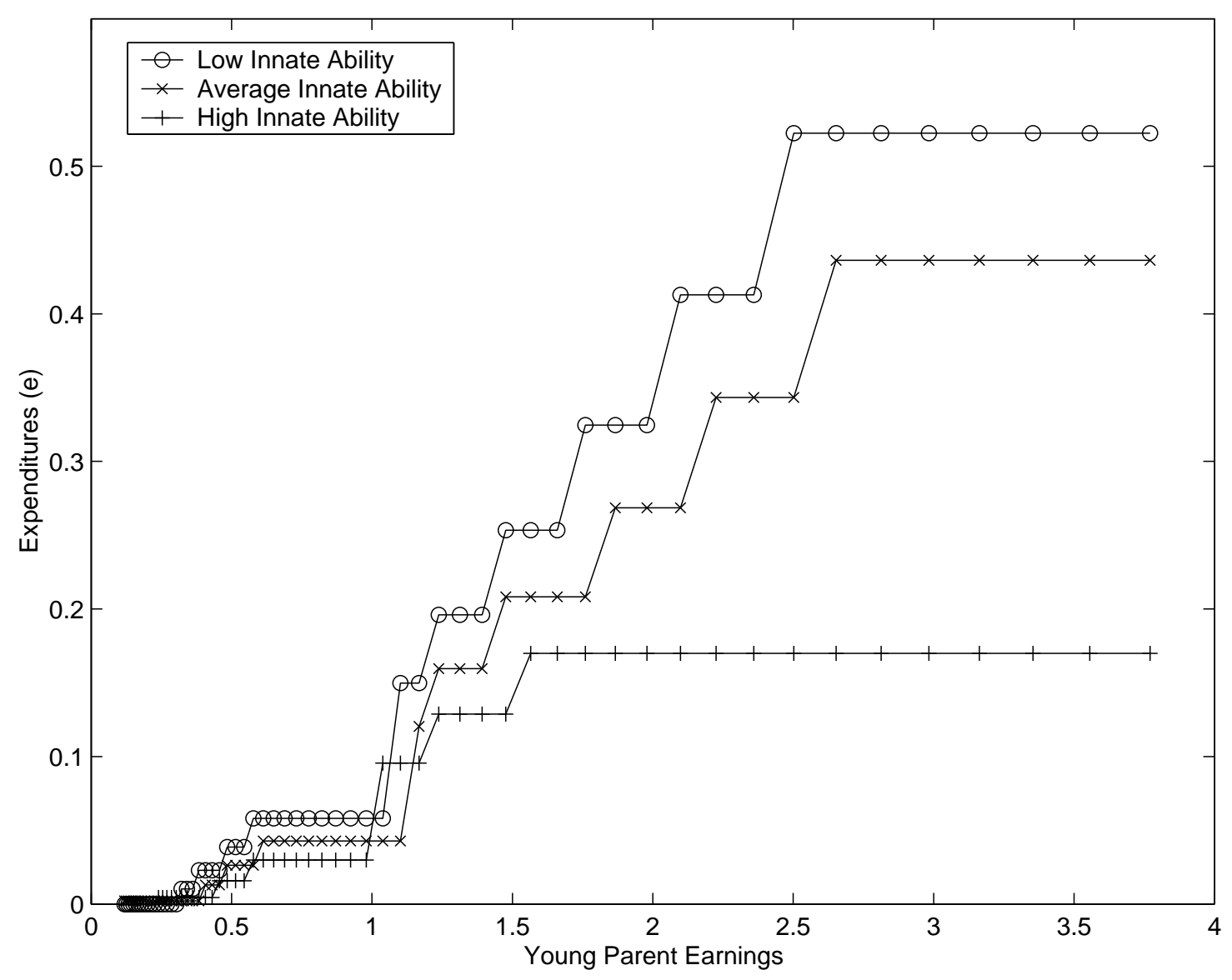


Figure 3: College Enrollment Policy
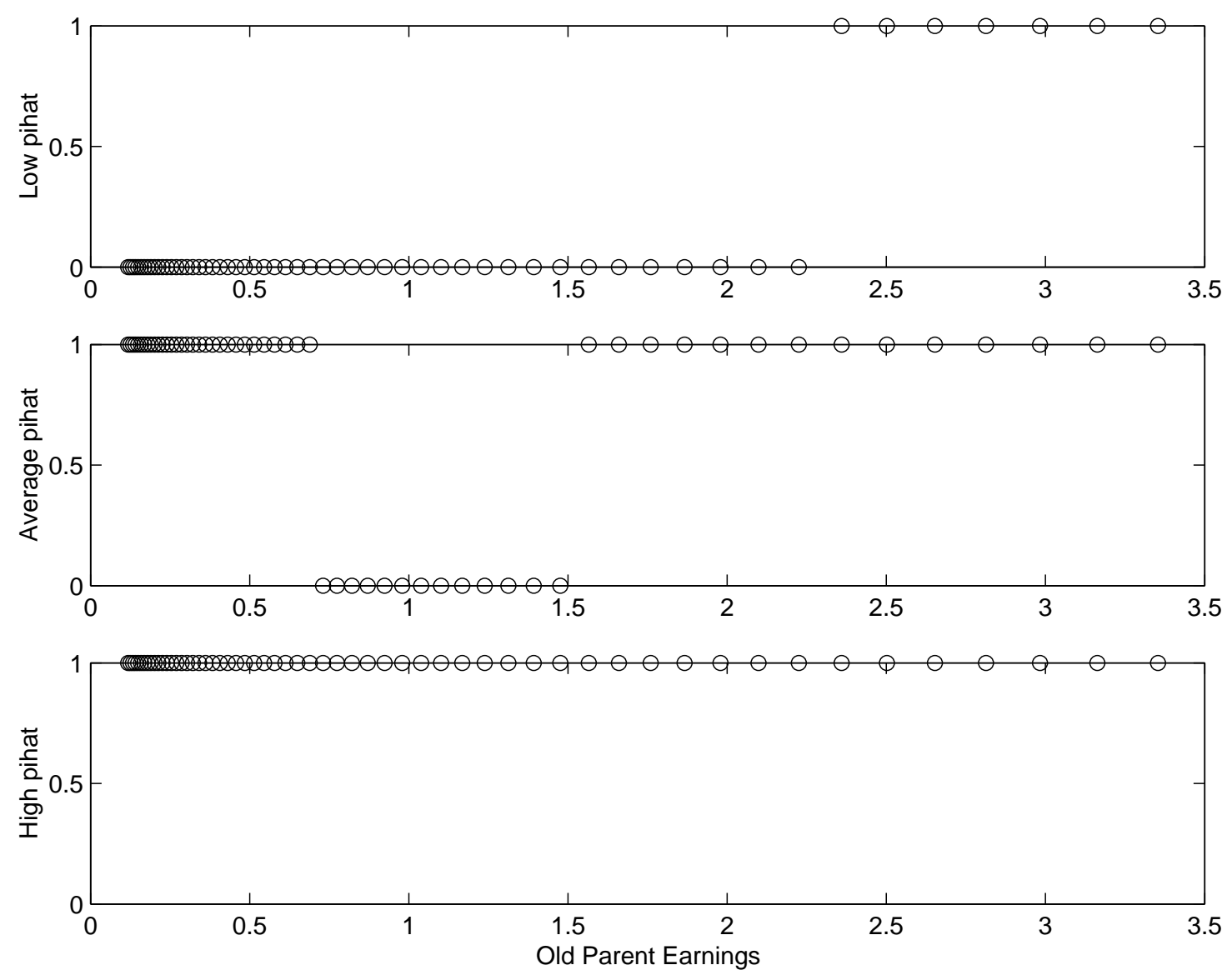
Figure 4: Enrollment and Completion Rates

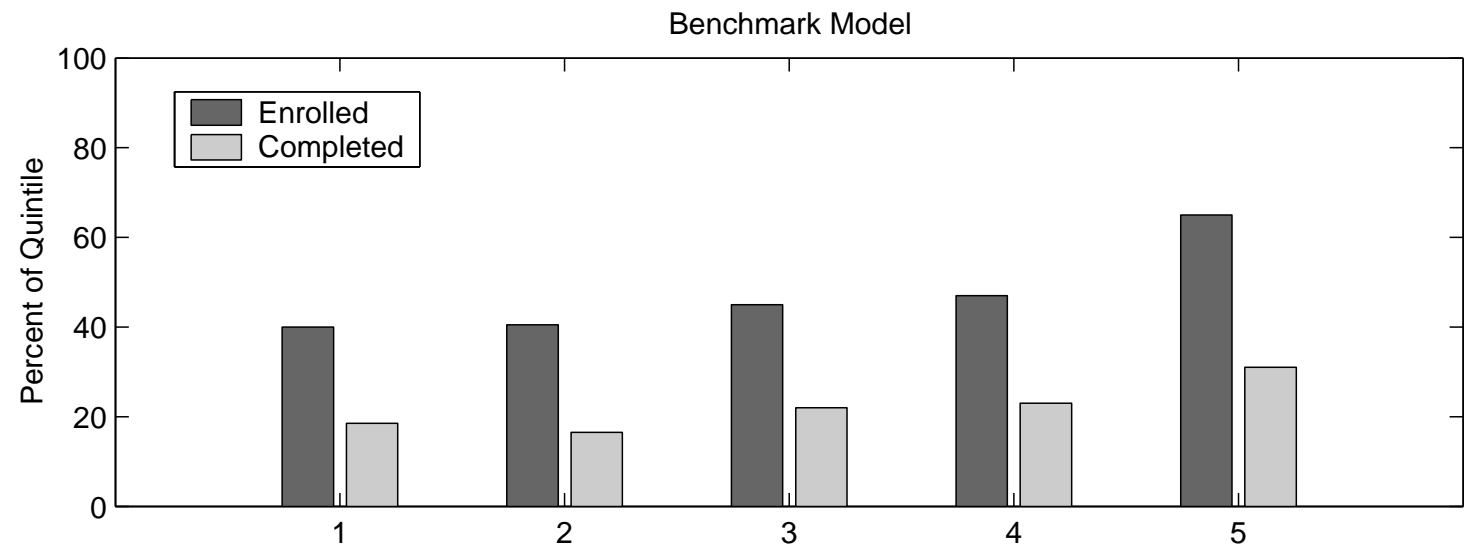

Data from Manski (1992)

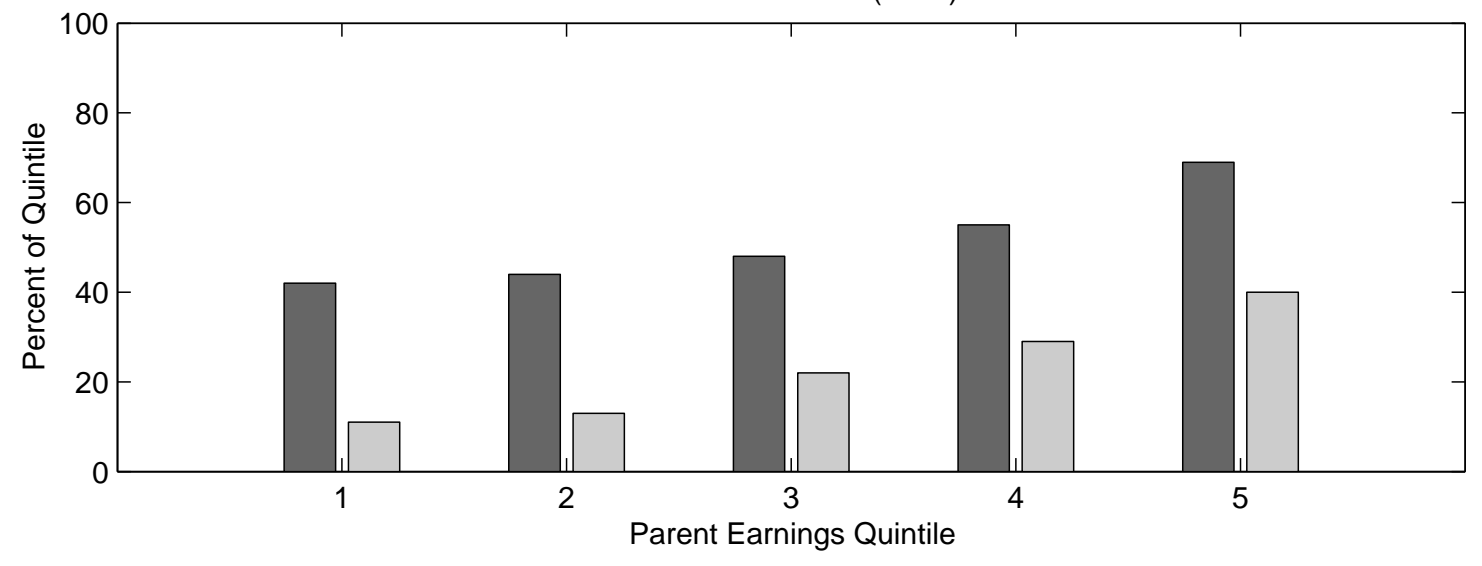


Figure 5: Ability and Human Capital: No Innate Ability Persistence

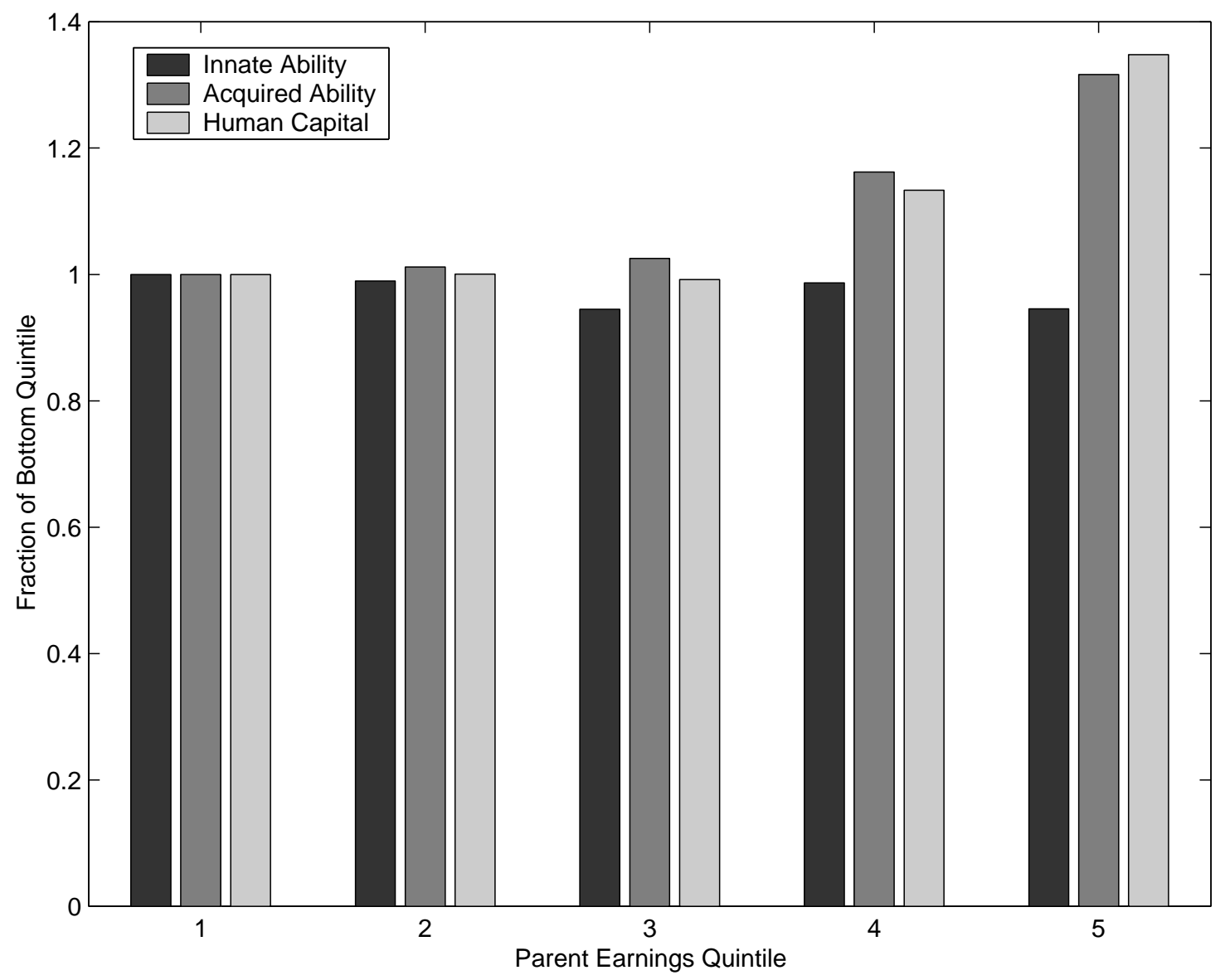


Figure 6: Enrollment Rates in Different Economies
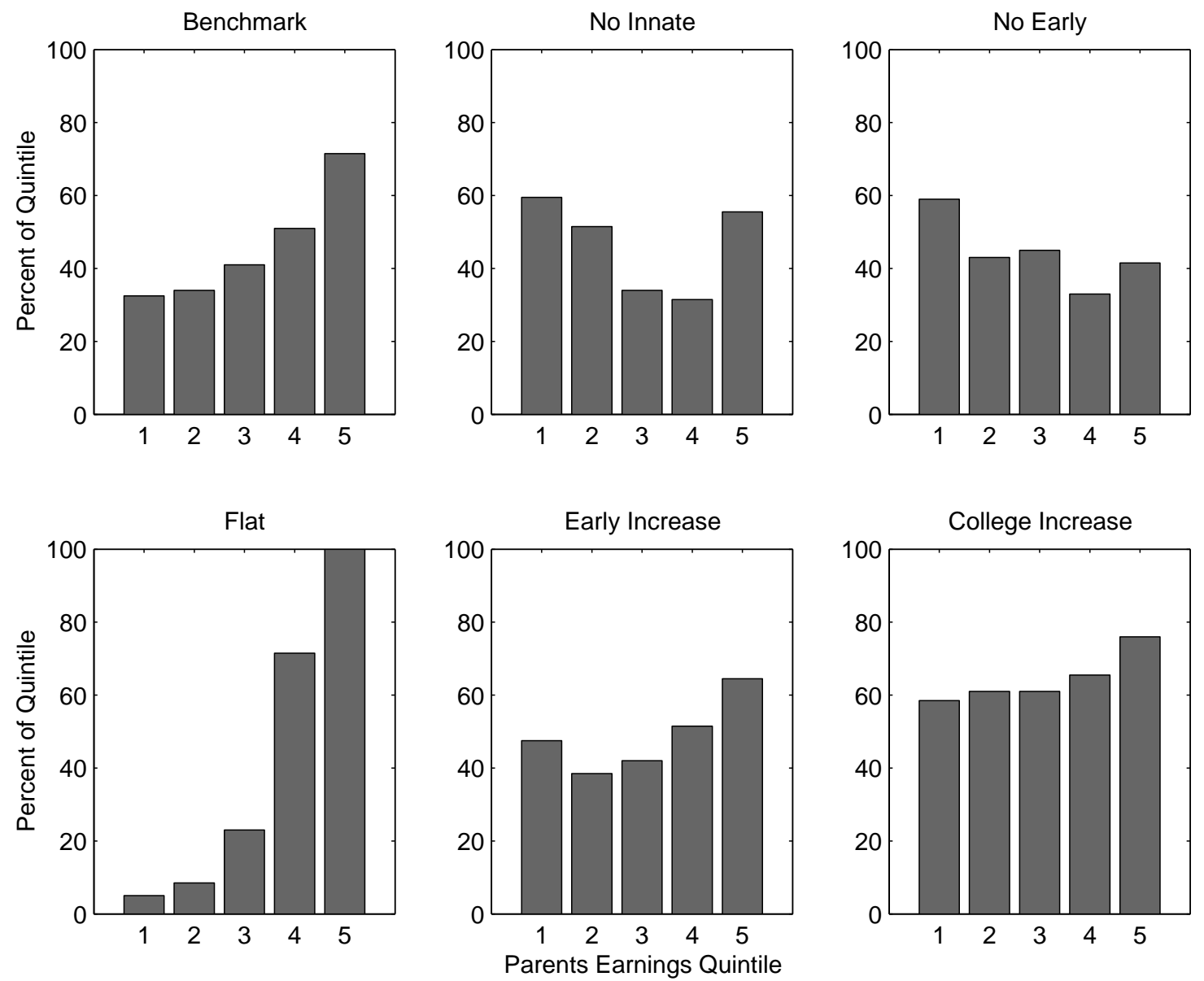
Figure 7: Completion Rates in Different Economies
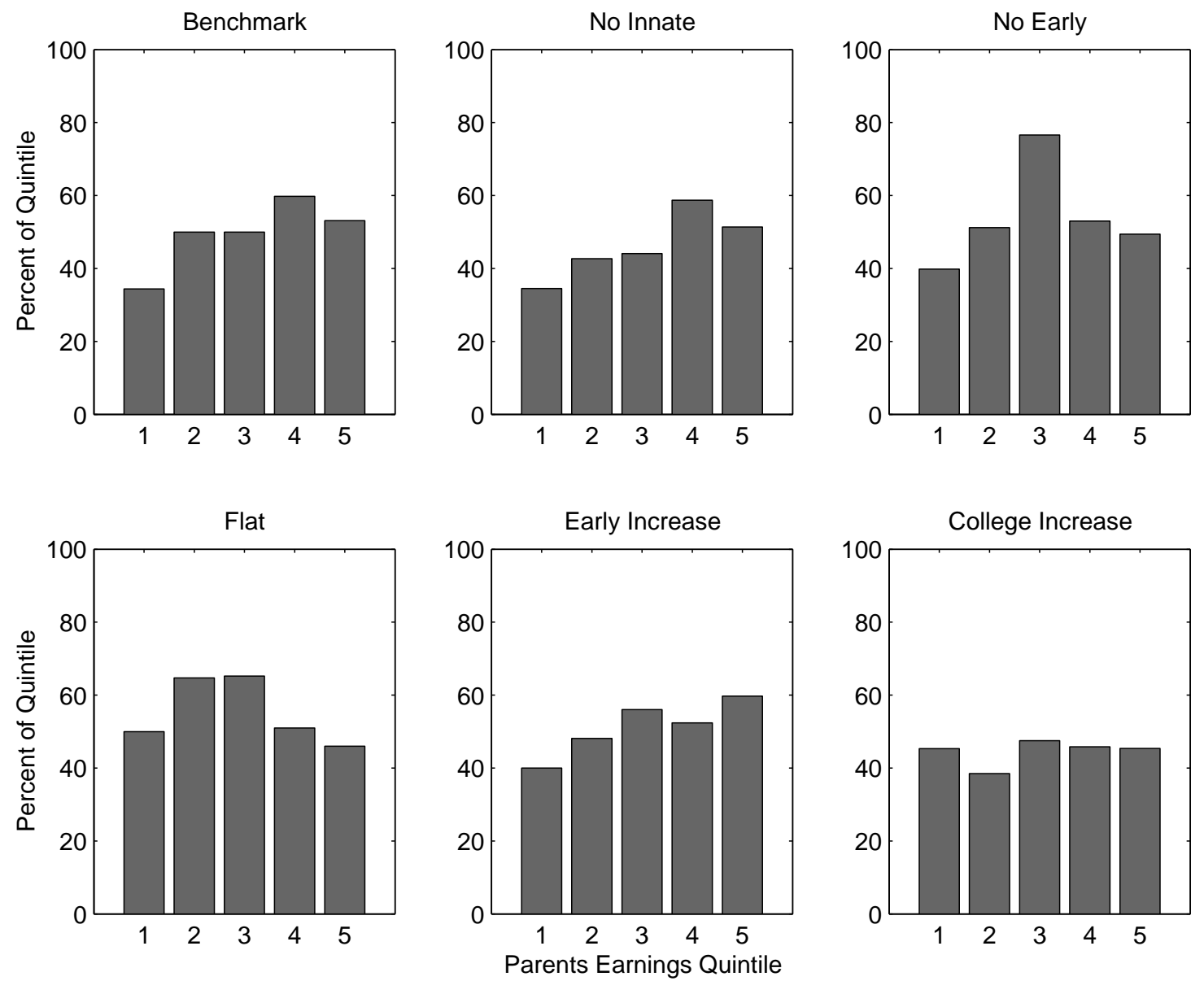